\title{
Article
}

\section{Value-Driven Design Framework for Competitive Aviation Markets}

Desai, Abdullah, Vengadasalam, Lavanan, Hollingsworth, Peter and Chinchapatnam, Phani

Available at http://clok.uclan.ac.uk/28723/

Desai, Abdullah ORCID: 0000-0002-4389-9939, Vengadasalam, Lavanan, Hollingsworth, Peter and Chinchapatnam, Phani (2019) Value-Driven Design Framework for Competitive Aviation Markets. Journal of Aircraft, 56 (4). ISSN 0021-8669

It is advisable to refer to the publisher's version if you intend to cite from the work. http://dx.doi.org/10.2514/1.c034829

For more information about UCLan's research in this area go to http://www.uclan.ac.uk/researchgroups/ and search for <name of research Group>.

For information about Research generally at UCLan please go to http://www.uclan.ac.uk/research/

All outputs in CLoK are protected by Intellectual Property Rights law, including Copyright law. Copyright, IPR and Moral Rights for the works on this site are retained by the individual authors and/or other copyright owners. Terms and conditions for use of this material are defined in the policies page.

\section{CLoK}

Central Lancashire online Knowledge www.clok.uclan.ac.uk

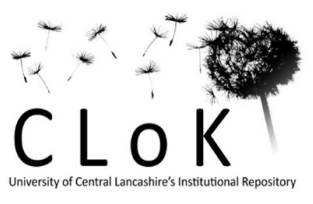




\title{
Value-Driven Design Framework for Competitive Aviation Markets
}

\author{
Abdullah A. Desai * and Lavanan Vengadasalam ${ }^{\dagger}$ and Peter Hollingsworth ${ }^{*}$ \\ The University of Manchester, Manchester, M13 9PL, United Kingdom \\ Phani Chinchapatnam $\$$ \\ Rolls-Royce plc, Derby, DE24 8BJ, United Kingdom
}

\begin{abstract}
Determining the "best" aircraft design for a given market segment is a challenging proposition. In this paper, a Value-Driven Design framework is created to illustrate how economic theory can be used to assess business strategies and engineering solutions within the civil aviation industry. The framework addresses a number of assumptions inherent within Surplus Value theory and compares them through a commercial aviation case study, for which the potential market size is highly uncertain. The case study demonstrated that without addressing these assumptions, a potential $380 \%$ difference in program Surplus Value was calculated. More specifically, the manufacturer value of the aircraft program can be calculated incorrectly by up to $900 \%$. This was determined by creating a multi-stage, non-cooperative game to characterize the behaviour of the commercial aviation industry to capture the effects of design parameters on the program value against different levels of competition from direct and adjacent markets.
\end{abstract}

\section{Nomenclature}

$$
\begin{aligned}
S V & =\text { Surplus Value } \\
N & =\text { Market Size } \\
D & =\text { Discount Factor } \\
U & =\text { Utilization } \\
R & =\text { Revenue } \\
C & =\text { Cost } \\
T & =\text { Program Lifespan } \\
t & =\text { Year }
\end{aligned}
$$

\footnotetext{
AIAA.

"PhD Student, School of Mechanical, Aerospace and Civil Engineering, George Begg Building, The University of Manchester, Student Member

${ }^{\dagger} \mathrm{PhD}$ Student, School of Mechanical, Aerospace and Civil Engineering, George Begg Building, The University of Manchester, Student Member AIAA.

† Lecturer in Aerospace Engineering, School of Mechanical, Aerospace and Civil Engineering, George Begg Building, The University of Manchester, Senior Member AIAA.

${ }^{\S}$ Team Leader, Engineering and Technology Cost Methods, Rolls-Royce plc.
} 


$$
\begin{array}{ll}
\sigma & =\text { Discount Factor } \\
V & =\text { Value of Product }
\end{array}
$$

Subscripts

$$
\begin{aligned}
& m=\text { Manufacturer } \\
& a \quad=\text { Airline } \\
& \text { dev }=\text { Research, Development, Test \& Evaluation } \\
& \text { man }=\text { Manufacture }
\end{aligned}
$$

\section{Introduction}

$\mathrm{T}$ o design, develop and certify a new aircraft involves great planning not only in terms of engineering but also in the organization and management of hundreds of engineers collaborating worldwide [1]. Even with the latest design methodologies, the Airbus A380 and Boeing 787 Dreamliner flagship aircraft programs of the commercial aviation world suffered from schedule delays, budget overruns, functional quality problems, and missed sales targets [2-5]. Issues like these are not only limited to aviation but are common problems in the broader engineering world [6].

Traditional design engineering methods are based upon meeting a set of requirements, which are extracted from attributes such as performance, cost, and time. However, even with such specific requirements, program overruns and failures continue $[6,7]$. This is because requirements are defined in the wrong manner; requirements inform design engineers of what not to do, rather than what design engineers should do [8]. For example, consider two high-level cost and weight requirements. These requirements provide no guidance as to which is the best or most preferred design, only a satisfactory design space [9]. Within this design space, which design is the best? A design with a high weight and low cost, or a design with low weight and high cost? Both designs are within the requirements, but the requirements lack the necessary information to select the "best" design. This results in a highly subjective and inconsistent decision-making process not only during the design stages but across the Product Life-Cycle (PLC) [7].

\section{Value-Driven Design and Surplus Value Theory}

Traditionally, Large-Scale Complex Engineered Systems (LSCES) such as aircraft programs are developed within the Systems Engineering (SE) paradigm, which typically utilize a Requirements-Based Engineering Design (RBED) methodology $[10,11]$. Within RBED, requirements are used to represent stakeholder's preferences, which guides design engineers to create a suitable design space. However, LSCES across the engineering spectrum are commonly prone to time and cost overruns, with many resulting in catastrophic commercial failures [6]. This highlights the importance in correctly applying SE and understanding the inherent limitations of RBED methodologies.

In order to address the issues faced by LSCES, many researchers believe that the future of LSCES design require contributions from a range of disciplines, placing equal importance on the technical and social fields [12-14]. These 
researchers promote the use of a Decision-Based Engineering Design (DBED) methodology, which incorporates decision theory technique such as Expected Utility (EU) [8, 15-17].

A DBED methodology provides the necessary information to create an objective decision-making process under uncertainty and risk $[15,17,18]$. The methodology removes requirements, which not only opens the design space but also encourages better analysis to rank design alternatives, where the higher the value, the better the design. This enables design engineers to objectively select the best option from a set of alternatives and create the most value for stakeholders. Furthermore, due to uncertainty and risk, new information throughout the design process can be used to update the design, creating an informed decision-making process. This is a vast improvement over RBED, where once the requirements are set, they are often contractual that cannot be changed or improved, this can result in LSCES to suffer from schedule, budget, and quality problems.

DBED methodologies, such as Value-Driven Design (VDD) are emerging within industry as they offer significant advantages over RBED. For example, DBED methodologies with single objective functions result in an objective, transparent, repeatable, and traceable decision-making method [10,19]. VDD is the most prominent DBED methodology; however, it was originally developed as an extension to SE in order to introduce economics into the decision-making process. Therefore, design engineers could utilize the current RBED methodology while using a value-based objective function for selecting optimum strategies [19].

The first complete utility-based DBED framework was developed by Hazelrigg [8] and later adapted by Collopy to incorporate a monetary objective function [20]. In the last few years, researchers have defined VDD methods specifically for the preliminary and detailed design of LSCES $[19,21,22]$. These value models mainly consist of monetizing design attributes using a transformation function to create an economic objective function. Using a monetary objective function is advantageous as most organizations are heavily dependent on financial metrics. Therefore, typical Value Models include Net Profit, Net Present Value (NPV), Cost, and Surplus Value (SV) [20].

$\mathrm{SV}$ is straightforward to understand and implement; requiring only knowledge on how design decisions will impact revenue and costs [23]. SV is analogous to the widely known NPV, which calculates the difference between the present value of cash inflows and the present value of cash outflows [24]. SV theory has been discussed in various literature and is well defined by various authors for use within aviation [19, 20, 22-27]. The main reason why SV is preferred to the other economic functions is because it encompasses all the key stakeholders in a single objective.

This paper starts with the same basic form of SV that was first described by Collopy [23] and formalized by Hollingsworth [22]. Equation 1 calculates the SV of an aircraft program within the commercial aviation industry.

$$
S V=D_{m} N\left[D_{a} U\left(R_{f}-C_{f}\right)-C_{m a n}\right]-C_{d e v}
$$

$\mathrm{SV}$ in the commercial aviation industry can be considered as the total profit of the aircraft manufacturer, engine 
manufacturer, and purchasing airline [23]. The manufacturer and airline discount multipliers are functions of the respective discount rates and the program duration or investment horizon. Discounting is a technique used to compare costs and benefits that occur in different time periods [28]. This is required to sum the future cash flows over the PLC to the present day value. The means of determining the discount multipliers for each entity is given in Equation 2, provided by Sutcliffe and Hollingsworth [29].

$$
D_{m, a}=\frac{1}{\sigma}-\frac{1}{\sigma(1+\sigma)^{T}}
$$

Equation 1 represents the calculation of SV for an aircraft program, which simply is equal to program revenue minus the program costs. Figure 1 illustrates the split in SV amongst the operators and manufacturers. Competition between the manufacturers and operators determine the split of SV; however, this information is not included within the equation.
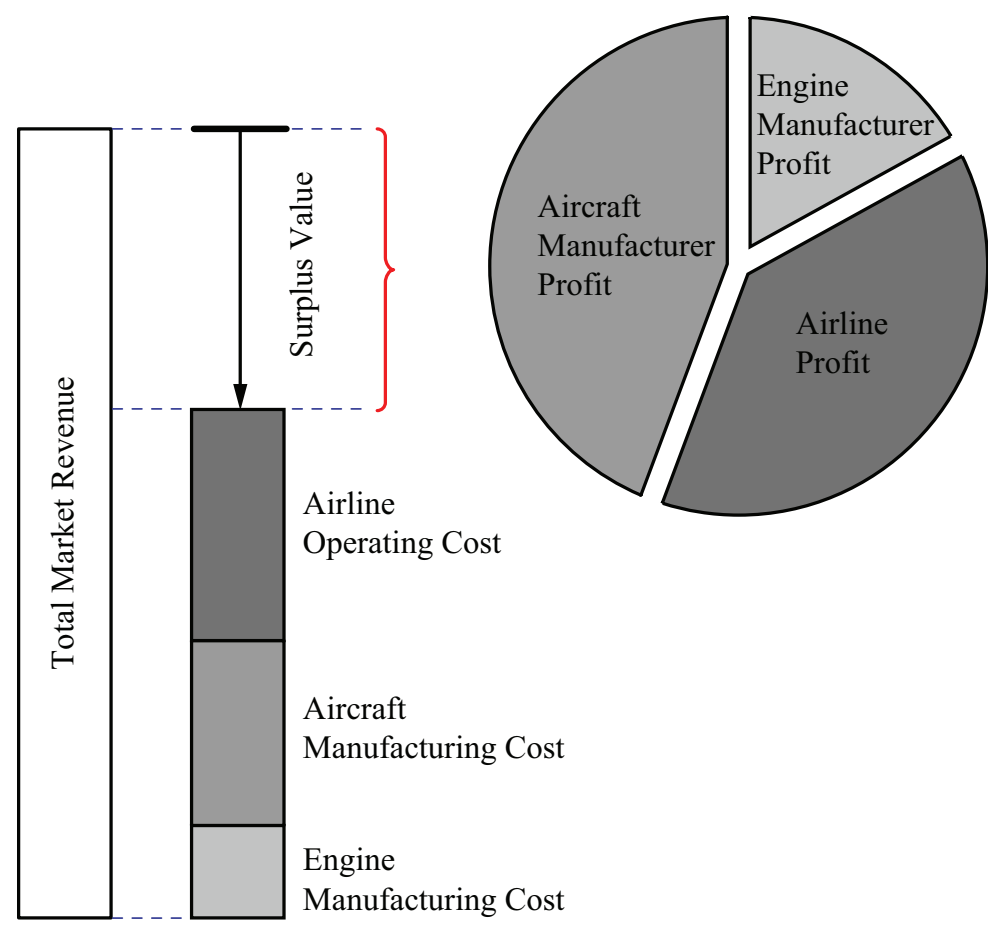

\section{Fig. 1 Illustration defining SV, including the splits in profit and cost between the key stakeholders of an aircraft program. Adapted from Cheung et al. [19].}

An objective function, such as SV, rationalizes the decision-making process, enabling design engineers to easily evaluate different alternatives and select the best option from a set of alternatives [19]. SV unifies the design method by considering all the key stakeholders across the PLC through one objective function [23]. This allows design engineers to make better trade-offs for all the stakeholders and ensure that the best overall system is designed, rather than combining many optimal components in the hope of an optimal design, or creating an acceptable design within a set of requirements.

The preferred objective function within commercial aviation is SV. However, many researchers believe that SV does 
not capture the true value of the design. Therefore, many question its suitability [30]. Hollingsworth [22] investigates the derivation of the SV equation and provides eight assumptions inherent to its formulation that need to be addressed. This paper addresses three of the major assumptions, which include:

1) Linking future market demand to the aircraft design on offer.

2) Future revenues and costs trend with time.

3) Multiple manufacturers and airlines to represent competition.

The proposed framework addresses these assumptions by utilizing elements of game theory principles to create a multi-stage, non-cooperative game to characterize the key players within the commercial aviation market. By replicating the behaviour of the market environment, the aircraft development, sales and operations become dependent on the aircraft design and the amount of the market it can capture. Within the proposed framework, as in the real world, the demand for new aircraft is created by the airlines, who decide between three alternative options regarding their fleet each year: buy a new aircraft model, buy the competitor's new aircraft model, or choose not to buy either. The airlines decide the option and the number of aircraft to buy depending on which provides the most utility, in other words, the one which provides the most profit. Therefore, if there is no demand to buy a new aircraft then the program from the manufacturers' perspective will fail. As the demand for a new aircraft design is dependent on the airlines' decision to buy, the revenue earned by the manufacturers will also be affected. Under these conditions, the airline revenue will not be the same from year to year, as different airlines will buy new aircraft depending on their fleet, route structure and profitability.

\section{Value-Driven Design Framework}

A Value-Driven Design framework was first presented by Desai et al [31] to design aircraft for non-traditional markets. A simple first order analysis was presented to demonstrate the challenges of developing a non-traditional aircraft, consisting of only reoccurring operating costs and neglecting any capital and fleet associate fixed costs.

Figure 2 illustrates the proposed framework, including the models required to replicate the behaviour of the key players within the commercial aviation market. The framework utilizes four key levels, which include the passengers, airlines, aircraft manufacturers, and engine manufacturers. Attributes of the design within the framework are determined by sequentially working through each modelling level. Once all the attributes are determined, the models are integrated to calculate the value of the design.

The proposed framework builds upon the aircraft system hierarchy, developed by Cheung et al. [19], and includes the flow of information to and from a focused entity, as proposed by Vengadasalam et al. [32]. Information between the models or key players is split into primary and secondary levels of importance. For example, a primary flow of information is between the aircraft manufacturer and airline, and a secondary flow of information is between the aircraft manufacturer and the passengers. These interactions are highlighted to illustrate how information is passed along the framework. 


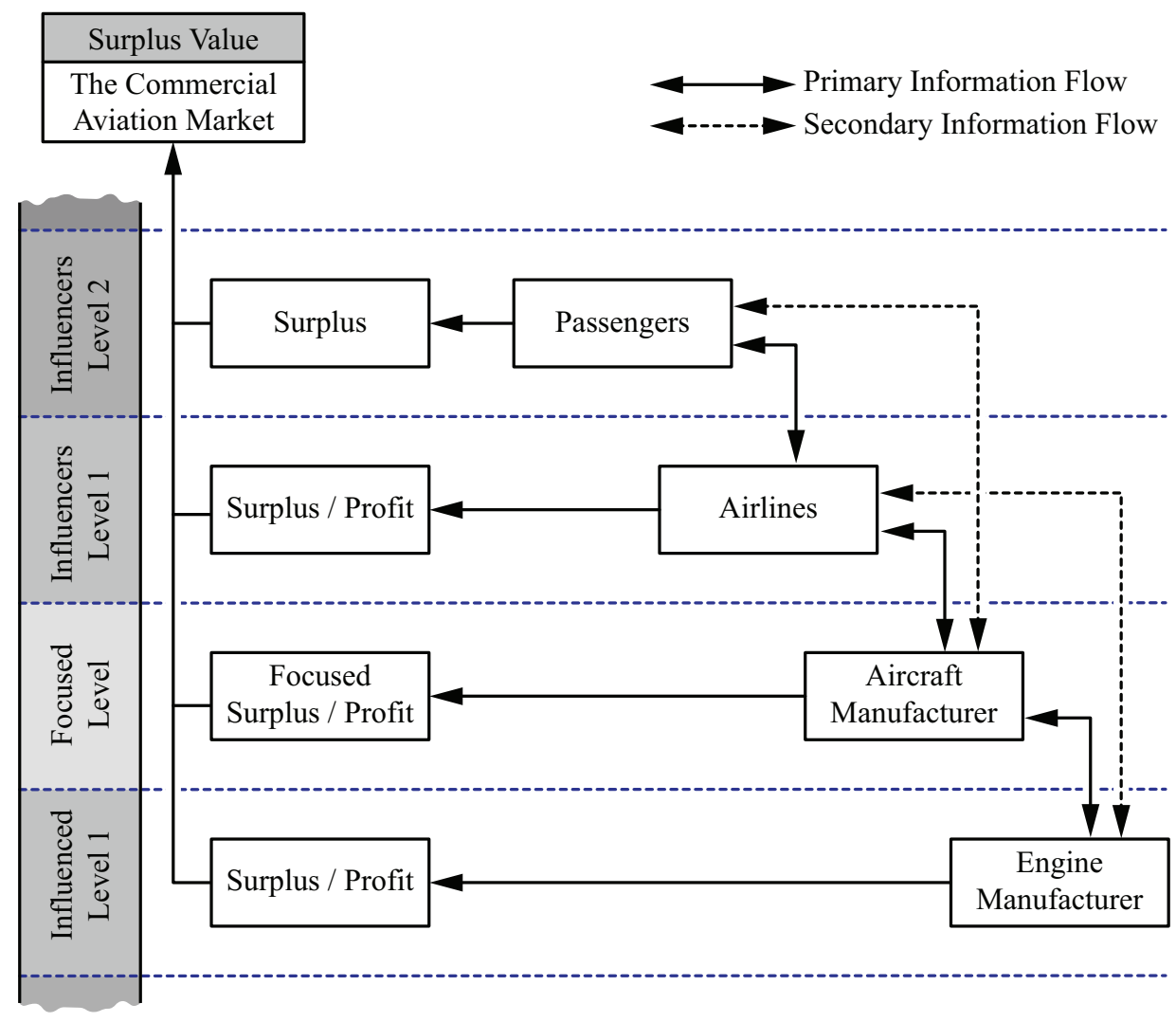

Fig. 2 Proposed VDD framework including the models required to characterize the behaviour of the key players within the commercial aviation market. The aircraft manufacturer is the focused level within this example; however, this can be changed to create a scenario from the perspective of any key player.

\section{A. Passenger Travel Model}

The passenger travel model is essentially a database relating to every aspect of the passengers and their travel decisions. This information is flowed down to the airlines and the manufacturers. The airlines are interested in information regarding the route, which include, origin, destination, routes available, routes chosen, price paid, and payload carried. This information can help in finding any seasonal travel demands and the general trend over time. The manufacturers would also use similar information to design the most suitable aircraft to appeal to the airlines. For the framework passenger model, publicly available sources of data are used to develop the travel trends, which include The United States Department of Transportation Bureau of Transportation Statistics (BTS) Form 41 [33].

The BTS data is used to build a starting point for the passenger travel model, which assumes the number of passengers on a given route will not decrease with a constant ticket price. To predict the future passenger demand, the framework incorporates a $2 \%$ yearly increase in the number of passengers travelling on the same route. The BTS data demonstrates a generally upwards trend of passenger travel ranging between $\pm 6 \%$. A linear trend is applied within the framework in order to generate a consistent market demand across all the scenarios investigated. Therefore, this simplifies the influence of the world markets on the value of the aircraft design. 


\section{B. Airline Model}

The airline model uses information from the passenger travel model to determine which routes to operate, how to connect destinations, the aircraft types to operate, the level and frequency of service, and most importantly the ticket price. An airline route structure is not only dependent on passenger travel demands, but also the type of airline, the aircraft types available to buy from manufacturers, and the competition from other airlines.

The airlines included in the framework are three legacy carriers similar to, United Airlines, Delta Airlines, and American Airlines, and a Low Cost Carriers (LCC), similar to Southwest Airlines. These four carriers were selected as they transported over 80\% of the total passengers within the American market in 2017 [33]. However, these airlines are also representative of other legacy carriers such as British Airways, KLM, Air France, and LCC, such as JetBlue, easyJet, and Ryan Air.

The BTS data provides the route structure, fleet utilization, and key financial metrics for each airline. This data is used to recreate the fleet and route structure with a typical load factor. The airline route structure is also dependent on the new aircraft types available to buy, and the competition from other airlines. Therefore, the route structure and corresponding fleet of each airline can change throughout the scenario to create the highest value.

\section{Aircraft and Engine Manufacturer Model}

The manufacturers model includes information relating to the performance and economics of the current and future aircraft. This information is used by the airlines to determine their route structure and profitability. Performance parameters include the payload-range capabilities of each aircraft along with the fuel burn and flight time for any given flight condition. These are used to determine the cost to the airline of any given flight. Additional economic parameters include the acquisition costs of new aircraft and the residual value of all the aircraft over time. This data is used to calculate the aircraft value when a transaction takes place between the aircraft manufacturer and airline.

Within the framework, a number of aircraft models are created using a NASA software called Flight Optimization System (FLOPS) [34]. These FLOPS models represent the current and new, Boeing 737, 757, 767, 787; and Airbus A320, A321, A330 families. To validate the performance of the aircraft models, the Maximum Take-off Weight (MTOW), Operating Empty Weight (OEW), and payload-range capabilities are compared with the data provided in the Aircraft Characteristics for Airport Planning (ACAP) and Flight Crew Operations Manual (FCOM) documents [35-50]. The models are validated to 5\% of the listed payload-range capabilities, and fuel burn over time at different altitudes.

\section{Value Model}

The total market SV of a commercial aircraft program is equal to the total Net Present Value (NPV) of all the manufacturers and operators within the aviation market. To calculate a NPV, all future profits and costs are discounted over the event horizon and totalled. In the case of the Manufacturer Net Present Value (MV), the profits are discounted 
over the PLC and for the Airline Net Present Value (AV), the profits are discounted over the investment period. Equations 3 and 4 are based upon Equation 1, which calculate the MV and AV.

Manufacturer Net Present Value (MV): The sum of the list price minus the manufacturing costs, multiplied by the total number of aircraft sold to the airlines over the course of the program life, minus the total Research, Development, Testing and Certification (RDT\&C) costs. This applies to each new engine and aircraft program by the respective manufacturer.

$$
S V_{m(i)}=D_{m(i)} N V_{n e w(i)}-C_{m a n(i)}-C_{d e v(i)}
$$

Airline Net Present Value (AV): The sum of the revenue from ticket sales and the sales of old aircraft, minus the cost of operating the airline route structure and expenditures for new aircraft. This applies to each individual airline.

$$
S V_{a(i)}=D_{a(i)} U\left(R_{f}-C_{f}\right)+\left(V_{\text {new }}-V_{\text {old }}\right)
$$

The variables within the SV equation requires information regarding the revenue, cost, depreciation, amortization, and taxes for each airline and manufacturer. This is achieved by creating models to calculate the specific revenues and costs for each entity modelled within the framework.

\section{Revenue Model}

Within the framework, there are three revenues to be calculated:

1) Airline revenue produced by the whole fleet for each airline route structure.

2) Aircraft manufacturer sales of each new aircraft program.

3) Engine manufacturer sales of each new engine program.

Airlines make money from the sales of transportation of goods and people. Passengers are the primary revenue stream and the price they pay for tickets are dependent upon the trip distance, airline type, and seat classification. Using the BTS data, a relationship is created between the ticket price with respect to the airline type, airline fleet structure, and the aircraft operating the route. This is required because aircraft of the same type within a fleet, or between airlines, flown on the same route, on the same day, will not have exactly the same payload conditions. Airlines also rarely fly to the prescribed conditions of the manufacturer i.e. Maximum Payload or economic range. Therefore, using the average payload conditions from the BTS data allows the framework to appropriately estimate the utilization and revenue of each aircraft type. The total revenue for each airline is calculated across the entire route network each year.

Manufacturer revenue is primarily from the sales of a new aircraft and engines. The amount they sell will depend on the market demand, which is dependent on the acquisition price. 


\section{Cost Model}

Within the framework, there are three costs to be calculated:

1) Airline costs produced by the whole fleet for each airline route structure.

2) Aircraft manufacturer costs to develop and manufacture new aircraft.

3) Engine manufacturer costs to develop and manufacture new engines.

Airline costs are divided into Direct Operating Cost (DOC) and Indirect Operating Cost (IOC). DOC are expenses associated with operating the aircraft, which include fuel, oil, crew salary, fees, maintenance, depreciation, and insurance. Within the framework, the crew, fuel, and airport costs are modelled into a total cost per hour of flight. This cost per hour of flight is specific for each aircraft and airline type. The ownership costs such as depreciation, interest, and maintenance costs are handled at a fleet level, which depends on the aircraft type, average age of each aircraft type, and the number of aircraft within the fleet. As airlines change their fleets regularly to remain competitive, the DOC of a fleet will also change, depending on the average number and age of each aircraft type within the fleet.

IOC are expenses associated with the running of the airline, which includes the depreciation of ground facilities and equipment, sales and customer service, administrative tasks, and any additional overheads. The IOC are more difficult to estimate as they are dependent on airline operations; where LCC keep costs to a bare minimum and the legacy carriers pride themselves on providing the full service. Within the framework, the IOC is calculated as a multiplier of the DOC [51]. To differentiate between LCC and legacy airlines, these values are approximated as 1.3 and 1.75 respectively, found using the BTS data [33].

The FLOPS inbuilt cost analysis module calculates the DOC and IOC using the aircraft configuration, performance, and weights data. It can calculate the airframe RDT\&C cost, airframe production cost, engine RDT\&C cost, engine production costs, DOC, and IOC. This information is used by FLOPS to estimate a total PLC cost of the aircraft design. Within the framework, the RDT\&C and aircraft production cost from FLOPS is combined with an appropriate profit margin to calculate the acquisition price for the airlines. However, the DOC and IOC from FLOPS are not directly used within the framework apart from verifying the framework calculations. Therefore, the yearly DOC and IOC are checked against the airline financial data, found within the BTS database, to ensure the costs are appropriate.

\section{E. Competition Model}

Over the event horizon, competition occurs between the airlines and their fleets as they seek to fulfill the market demand. Introducing a new aircraft will also create new competition between aircraft in a bid to fly in the airline fleet. The aircraft that generates the highest profit on each route is selected within the fleet. This could either result in buying a new aircraft as it provides more AV or restructuring the fleet to utilize the best aircraft to generate the most value. Therefore, competition to an aircraft within the fleet can be categorized by direct replacements, such as Airbus narrow-body to replace a Boeing narrow-body, and by aircraft which are not essentially thought as a substitute, 
such as a wide-body aircraft to replace a narrow-body aircraft. Using this simplified representation of the market environment, the value of current and new aircraft and engine programs can be calculated at the individual program-level and enterprise-level.

\section{F. Framework Operations and Analysis}

A design engineer can introduce new aircraft designs within the framework to calculate the total SV, MV, and AV. The value of an aircraft is driven by the demand from the airlines. For example, airlines buy new aircraft, retire old aircraft, and restructure their fleet and route allocation each year to maximize the AV. The decision to replace or buy a new aircraft is purely economical; airlines will buy new aircraft when the current aircraft in the fleet provides less AV than a new aircraft. If a competition scenario is run, in which two or more new competing aircraft or engine options are available for the airlines to buy, then the SV of each program is calculated.

To operate the framework, the design engineer must first provide the initial conditions of each model. For the passenger travel model, the initial information required includes the origin and destination of each route available, the route demand, and ticket price of each route. For the airline model, the initial information required includes, the fleet size and utilization, the aircraft types available over the event horizon, and the number of aircraft available to each airline. For the manufacturers, the information required includes the design variables of the new aircraft programs, as listed in Table 1. To calculate the value to each key player, the payback period and discount rates also need to be defined.

Table 1 Representative optimization input design variables, which depict the key conceptual program-level decisions in generating a basic aircraft design.

\begin{tabular}{lll}
\hline Engine Variables & Aircraft Variables & Performance Variables \\
\hline Number of Engines & Number of Seats & Wing Area \\
Maximum Sea Level Thrust & Seats Abreast & Wing Aspect Ratio \\
Overall Engine Pressure Ratio & Composite Structure & Wing Sweep \\
Fan Pressure Ratio & Aircraft Mark Up & Thickness to Chord Ratio \\
Turbine Entry Temperature & Weight Parameter & Performance Parameter \\
\hline
\end{tabular}

The design engineer has the ability to include a number of airlines and a number of new aircraft programs, replicating as much or as little competition required for analysis. However, the design engineer must specifically assign each new aircraft program with a start year and end year of production, as this will determine the event horizon. There is also the option to assign the number of new aircraft available each year to the airlines. This is useful to simulate a limit in production or a backlog of demand. Finally, the design engineer can either create scenarios replicating the real world airline fleets or allow the framework to create the best revenue generating fleet for each airline's route structure.

Over the event horizon, an airline will buy new aircraft due to increased passenger travel demand or an aging aircraft becoming too expensive. The airlines will make this decision and restructure their fleet each year to maximize AV. At 
the end of each year of the scenario the airlines will purchase aircraft. These are delivered the following year. The reason an airline would decide to buy a new aircraft simplifies to a purely economic decision: if the new aircraft's acquisition price, discounted over the airlines payback period, is paid off and still provides more value than a current aircraft within the fleet, operating on a certain route, including both of their residual values when selling, then the airline will sell the current aircraft within the fleet to buy the new aircraft type. This is shown in Equation 5 .

$$
\begin{array}{r}
\frac{\left(V_{\text {new }(T)} N_{\text {new }}\right)}{(1+\sigma)^{T}}-\left(V_{\text {new }(t)} N_{\text {new }}\right) \\
>\sum_{t}^{T}\left(D_{a} U\left(R_{f}-C_{f}\right)\right)_{\text {new }} \\
> \\
\left(V_{\text {old }(T)} N_{\text {old }}\right)+\sum_{t}^{T}\left(D_{a} U\left(R_{f}-C_{f}\right)\right)_{\text {old }}
\end{array}
$$

Airlines do not make acquisitions based only on economic elements, other factors can also impact the decision-making process. For example, an airline's reputation can be increased by buying the newest, biggest, fastest, or luxurious aircraft. These factors are considered outside the scope of this research. However, it is important to recognize that these do form a part of the decision-making process for airlines and manufacturers.

Once the framework has run to the event horizon, it will calculate the value outputs of each key player including how many aircraft were sold, in which year and to whom. If the scenario includes two or more new competing aircraft or engine options, then the value outputs of each program is calculated. This provides the design engineer with the ability to compare programs to find the best option.

There are cases where the airlines may choose not to buy any of the new aircraft available, this can be due to numerous factors such as the aircraft price, performance, or suitability. However, optimization can be undertaken to maximize the value of the aircraft and engine design on offer.

\section{Middle of the Market Case Study}

The MoM is the cross-over point between the single-aisle and twin-aisle aircraft, between 180 and 250 seats. The only aircraft to fly within this market is the Boeing 757, which has been in operation for 33 years. In the past both Boeing and Airbus offered aircraft for this class; replacement options include smaller narrow-body aircraft such as the Airbus A320 and Boeing 737 or larger wide-body aircraft such as the Airbus A330 and Boeing 787. The Airbus A321neoLR and Boeing 737 MAX are designed as direct replacement options but as many as 700 Boeing 757 are still in operation today, and will need to be replaced over the next decade [52].

The MoM scenario was selected because manufacturers are uncertain regarding the market demand and the fundamental design of the aircraft. Therefore, this case study presents a unique opportunity to not only determine the 
improvements made upon the simple SV equation, but also demonstrate the effect on program value and market size due to competition and changes in the aircraft design. Therefore, this case study is broken down into 6 scenarios, which builds up the competition to replicate the MoM:

Scenario 1: No aircraft are available to buy from manufacturers within the market. Airlines can only optimise their starting fleet to maximise AV. All aircraft manufacturers cease to operate.

Scenario 2: Only the MoM aircraft is available to buy within the market. Airlines can only buy this new aircraft to renew their ageing fleets and meet the increasing passenger demand.

Scenario 3: The MoM and narrow-body aircraft are available to buy within the market. The competitor is a new high aerodynamic and technology level narrow-body aircraft, similar to a Boeing 737 MAX.

Scenario 4: The MoM and wide-body aircraft are available to buy within the market. The competitor is a new high aerodynamic and technology level wide-body aircraft, similar to a Airbus A330neo.

Scenario 5: The MoM, narrow-body, and wide-body aircraft are available to buy within the market. This scenario is the most representative of the competition faced in the MoM.

Scenario 6: The narrow-body and wide-body aircraft are available to buy within the market. This scenario represents the outcome without a dedicated MoM aircraft.

These scenarios are key in demonstrating how the framework addresses the SV assumptions. For example, in each scenario, as new competitors are introduced, the market demand of the proposed MoM aircraft changes. This addresses the fixed market demand assumption. The results also inherently addresses the assumptions of multiple manufacturers and airlines, whose future revenues and costs trend with time. It is important to note that the results are not representative of the actual outcome of the MoM market. Instead, the case study demonstrates how the framework can address the MoM uncertainty and risk and showcase the concept of using value for aircraft design.

\section{A. Simple Surplus Value Calculation}

For this paper, a notional derivative replacement aircraft is created, called the MoM A.1. MoM A.1 represents a new high aerodynamic and technology level narrow-body aircraft based on the Boeing 757, with a payload capacity of $50,000 \mathrm{lb}$ and a range of $4500 \mathrm{~nm}$. MoM A.1 is not representative of the best MoM design, rather it is just a potential design created to only demonstrate the process of the framework.

Using Equation 1, a simple program SV is calculated for MoM A.1. Hollingsworth [22] provides a manufacturer and airline discount rate of 0.12 and 0.25 respectively, which represents a program life of 23 years and a investment period of 9 years for the airlines. The total market size of 1000 aircraft is used, as quoted by Boeing [53]. Using a MoM A.1 FLOPS model calculates a manufacturing cost of \$140M per aircraft and a program RDT\&C cost of \$10B.

The simple SV equation only uses one mission to calculate the value of the aircraft program. This disregards the airline route structure and the ability to fly multiple or different routes over the event horizon. Therefore, a range of SV 
are calculated using the routes of the average, median, and economic of the Boeing 757 flights from 2014.

Table 2 SV calculation, using the simple SV equation, of the MoM A.1 aircraft for the mean, median, and economic Boeing 757 routes in 2014.

\begin{tabular}{lrrr}
\hline Route & Mean & Median & Economic \\
\hline Payload (1000 lb) & 57 & 52 & 51 \\
Range $(\mathrm{nm})$ & 1140 & 1957 & 3400 \\
Revenue per flight $(\$ 1000)$ & 99 & 95 & 111 \\
Cost per flight $(\$ 1000)$ & 22 & 22 & 54 \\
\hline Program SV (\$B) & 713 & 384 & 279 \\
\hline
\end{tabular}

A major issue when using the simple SV equation, taking into account all of its assumptions, is not knowing the split of value between the airline, and manufacturers. The issue with the split of value may not be so important if one entity encompasses the manufacturing and operation. However, the manufacturers and airlines are individual entities who maximize their own profits. Therefore, the simple SV analysis does not provide the necessary information to make informed decisions for each entity. Furthermore, Table 2 shows a difference in SV of over $250 \%$ or $\$ 440 \mathrm{~B}$ just by changing the route. This shows that the simple SV analysis is not only redundant due to the lack of information but also highly unreliable.

\section{Scenario 1: No new aircraft are available}

The framework operates the four airlines and their representative route networks over an event horizon, which equals the program production duration of 23 years. In this scenario, the airlines cannot buy any new aircraft because no manufacturers exist. This forces the airlines to maximize their starting fleets. Scenario 1 provides a baseline to compare AV and SV when new aircraft programs are available. Table 3 shows the total fleet size and utilization at the start and end of the first scenario.

Table 3 Total and individual fleet size, AV, and SV of the MoM case study scenario 1, which includes no new aircraft.

\begin{tabular}{lrrrrr}
\hline & \multicolumn{4}{c}{ Airline } & \multirow{2}{*}{ Total } \\
\cline { 2 - 5 } & A & B & C & D & \\
\hline Fleet Size (Year 1) & 649 & 629 & 660 & 575 & 2513 \\
Fleet Size (Year 23) & 649 & 597 & 613 & 559 & 2418 \\
\hline AV (\$B) & 394 & 752 & 542 & 538 & 2227 \\
\hline Market SV (\$B) & & & & & 2227 \\
\hline
\end{tabular}

Figure 3 corresponds with Table 3 to present the total fleet size and AV in each year of the event horizon within the first scenario. Note that the MV in Figure 3 is zero as there are no new aircraft programs within this scenario.

The total fleet size at the end of the first scenario is 95 aircraft less over the four airlines. This is due to the airlines optimizing their fleets and restructuring their route network to generate the highest AV. Older aircraft are either 


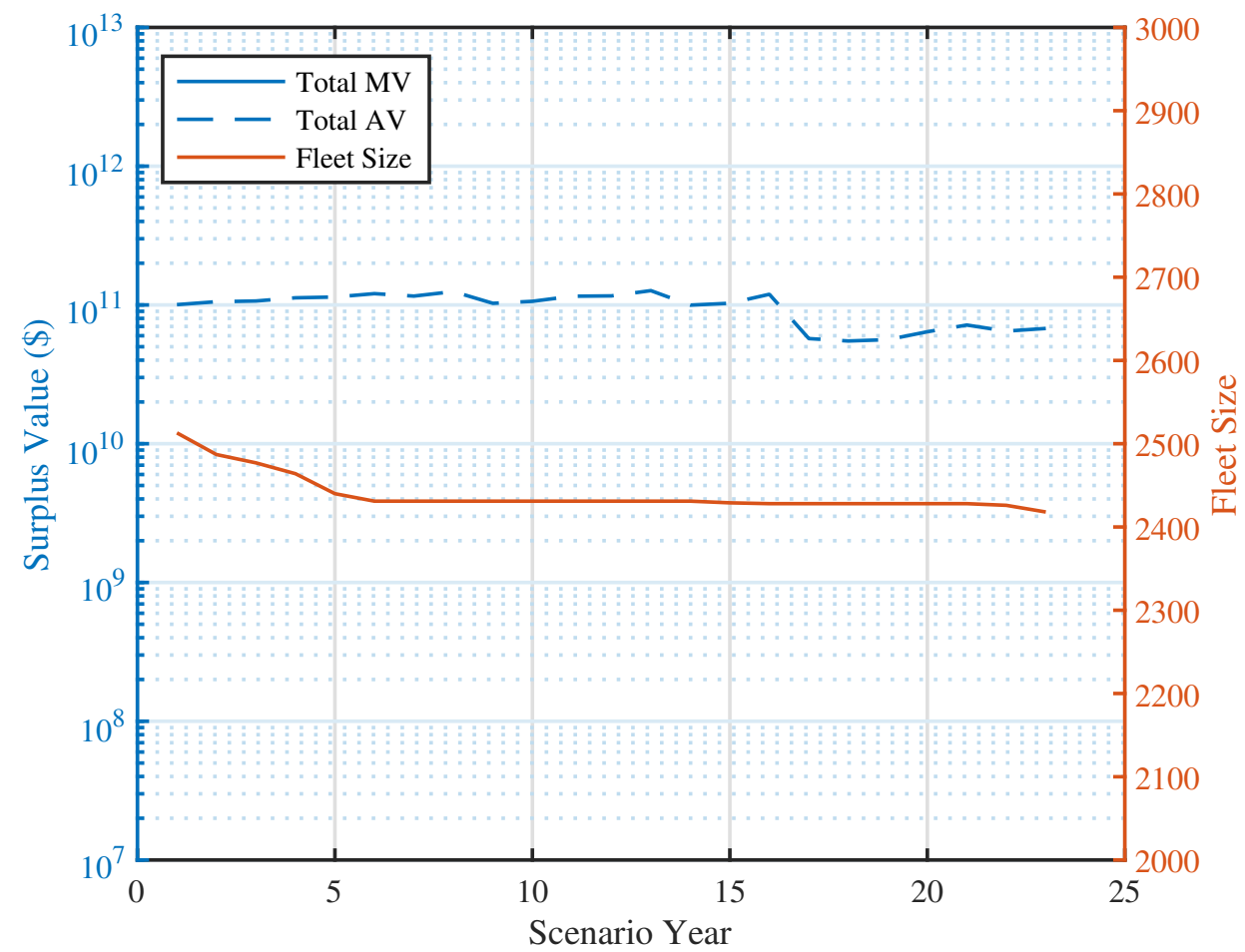

Fig. 3 Total fleet size and AV of each year within the MoM case study scenario 1, which includes no new aircraft.

redeployed or retired, which can result in some routes not being served or being partially served. The total market SV in this scenario is $\$ 2.2 \mathrm{~T}$, which is a combination of the total value of the commercial market including the AV and MV. This should not be confused with the SV of the MoM A.1 aircraft program calculated in Table 2, as that is concerning the single aircraft program. The total market SV includes the SV of all the aircraft operating within the market.

Figure 3 illustrates how the AV increases due to the increasing passenger demand until year 8 , where there are a number of steps of reducing AV. These downturns are associated with extending the life of older aircraft. At the end of life of an aircraft, the airline can either retire it, which will create an unserved route, or, pay for the increased maintenance costs to extend the life of the aircraft. As the total fleet size does not decrease during a majority of the downturns in $\mathrm{AV}$, this suggests that the aircraft life is extended as they provide more $\mathrm{AV}$ than if retired.

Figure 4 shows the same data as Figure 3, but includes the individual AV and fleet size. It illustrates when each airline retires an aircraft and how they restructure the fleet to generate the most AV. For example, the LCC Airline A, does not retire any aircraft within its fleet over 23 years. The AV of Airline A rises steadily for 13 years as the fleet is restructured to meet the rising demand. However, once aircraft within the fleet reach the end of its life, Airline A pays the maintenance penalty to extend the aircraft life, resulting in the declines in AV, as shown in years 13,16, and 17. 


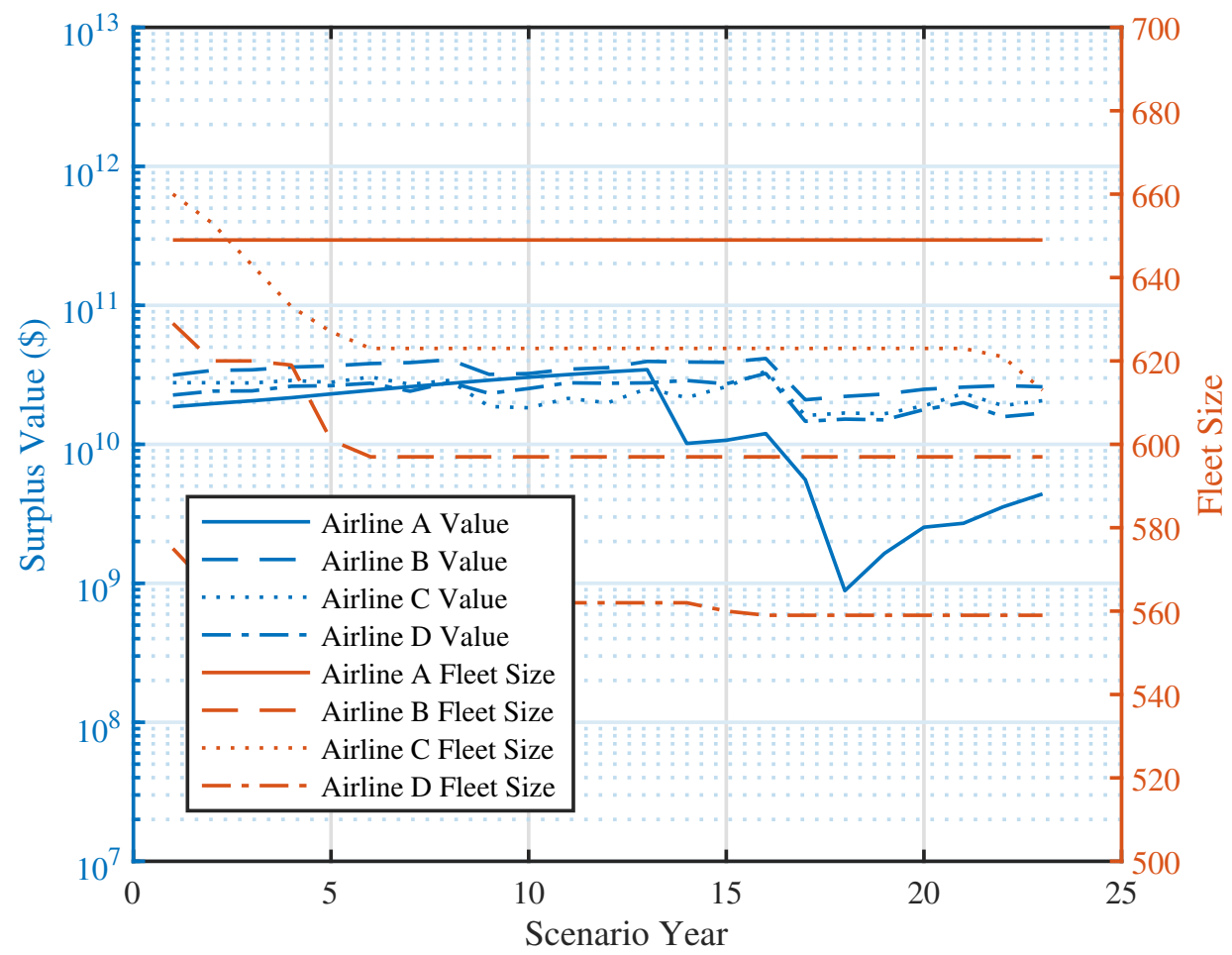

Fig. 4 Breakdown of the individual airline fleet size and AV of each year within the MoM case study scenario 1 , which includes no new aircraft.

Scenario 2: Introducing the MoM aircraft

The second scenario introduces the MoM A.1 aircraft used previously within the simple SV example. MoM A.1 is the only aircraft available to the airlines over the 23 year event horizon. Table 4 shows the total fleet size and utilization of the second scenario, which includes the split in value of the manufacturer and airline for the MoM A.1 aircraft.

Table 4 Total and individual fleet size, MV, AV, and SV of the MoM case study scenario 2, which includes the MoM A.1 aircraft only.

\begin{tabular}{lrrrrr}
\hline & \multicolumn{4}{c}{ Airline } & \multirow{2}{*}{ Total } \\
\cline { 2 - 5 } & A & B & C & D & \\
\hline Fleet Size (Year 1) & 649 & 629 & 660 & 575 & 2513 \\
Fleet Size (Year 23) & 663 & 647 & 680 & 535 & 2525 \\
\hline MoM A.1 Sold & 323 & 542 & 604 & 487 & 1956 \\
MoM A.1 AV (\$B) & 225 & 250 & 287 & 278 & 1041 \\
MoM A.1 MV (\$B) & 2.16 & 8.36 & 9.89 & 8.76 & 29.2 \\
\hline AV (\$B) & 475 & 949 & 750 & 803 & 2977 \\
\hline Market SV (\$B) & & & & & 3006 \\
\hline
\end{tabular}

In this scenario, the four airlines buy 1956 MoM A.1 aircraft. Airlines will use the MoM A.1 to replace any aging aircraft within their fleets as well as to meet the increasing passenger demand. This causes the total market SV to increase to $\$ 3 \mathrm{~T}$ as the airlines do not have to operate $23+$ year old aircraft. Furthermore, the MV from sales of the MoM 
A.1 aircraft also contribute to the total market SV in this scenario.

Figure 5 corresponds with Table 4 which presents the total fleet size and AV in each year of the event horizon. The program SV of the MoM A.1 is \$1.07T, of which \$29.2B is MV and the remaining \$1.04T is AV. This MV can be compared to the program SV calculated using the simple SV equation. In this scenario, there is a difference on average of over $230 \%$ between the framework and simple SV equation.

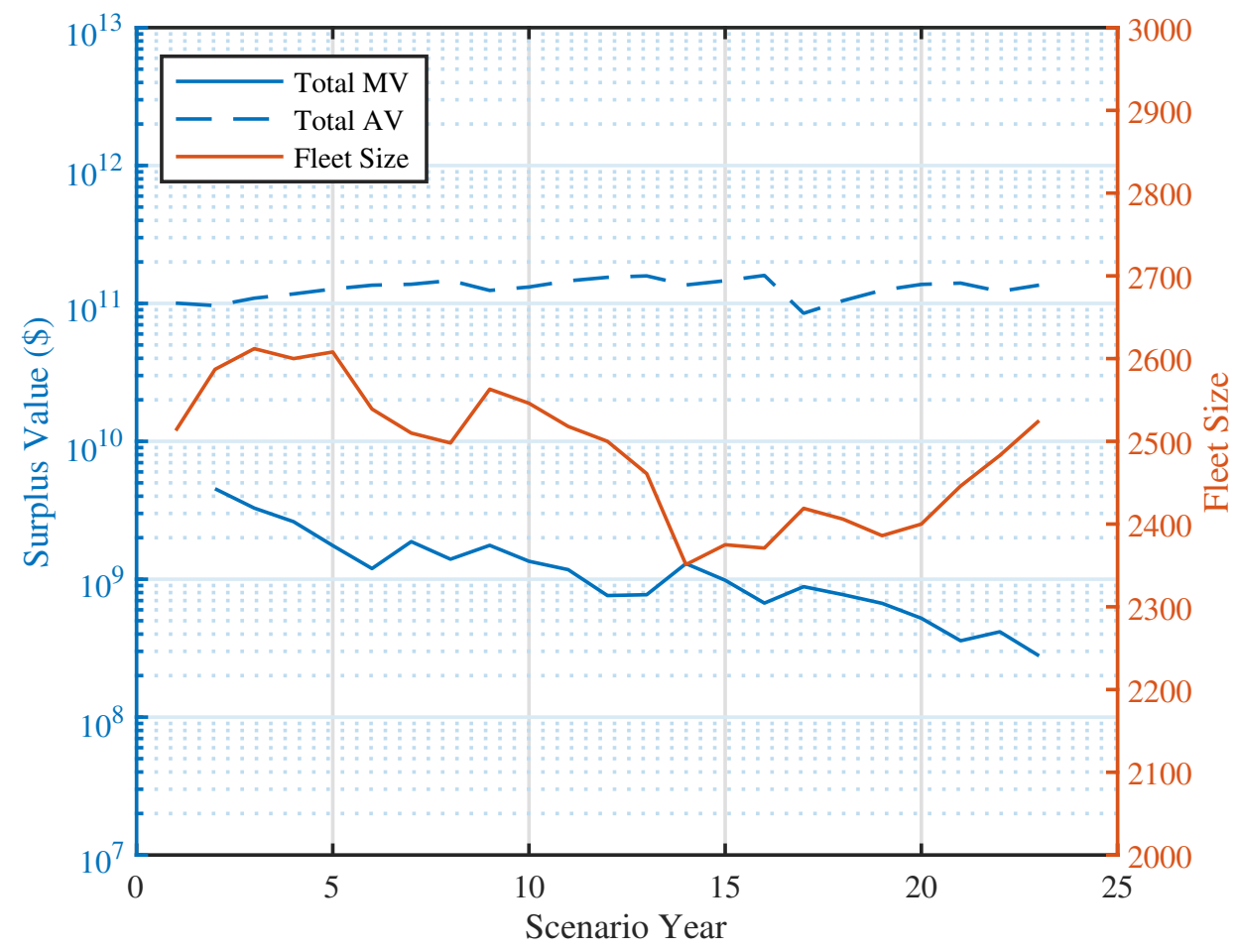

Fig. 5 Total fleet size and AV of each year within the MoM case study scenario 2, which includes the MoM A.1 aircraft only.

To determine the effect of the aircraft design on the market demand and the program value, a similar aircraft to MoM A.1 was created, called MoM A.2. MoM A.2 has the same capacity but has a lower aerodynamic and propulsive efficiency than MoM A.1.

In this scenario with MoM A.2, the total market SV reduces from \$3T to \$2.75T and the aircraft program SV reduces from $\$ 1.07 \mathrm{~T}$ to $\$ 767 \mathrm{~B}$. This is due to 356 fewer MoM A.2 sales, which can be attributed to the aircraft providing less benefit to the airlines, causing the airlines to hold onto older aircraft for longer. This is shown by the higher fleet size in year 23 of 2659, with 1600 MoM A.2 aircraft sold, compared to a 2525 fleet size in year 23, with 1956 MoM A.1 aircraft sold.

This is a key outcome as it shows that the framework addresses a major assumption of the simple SV equation. The results demonstrate that the market size and program value is dependent on the aircraft design on offer. However, these results are still considered basic as the scenario does not include any competition to the MoM aircraft on offer. 


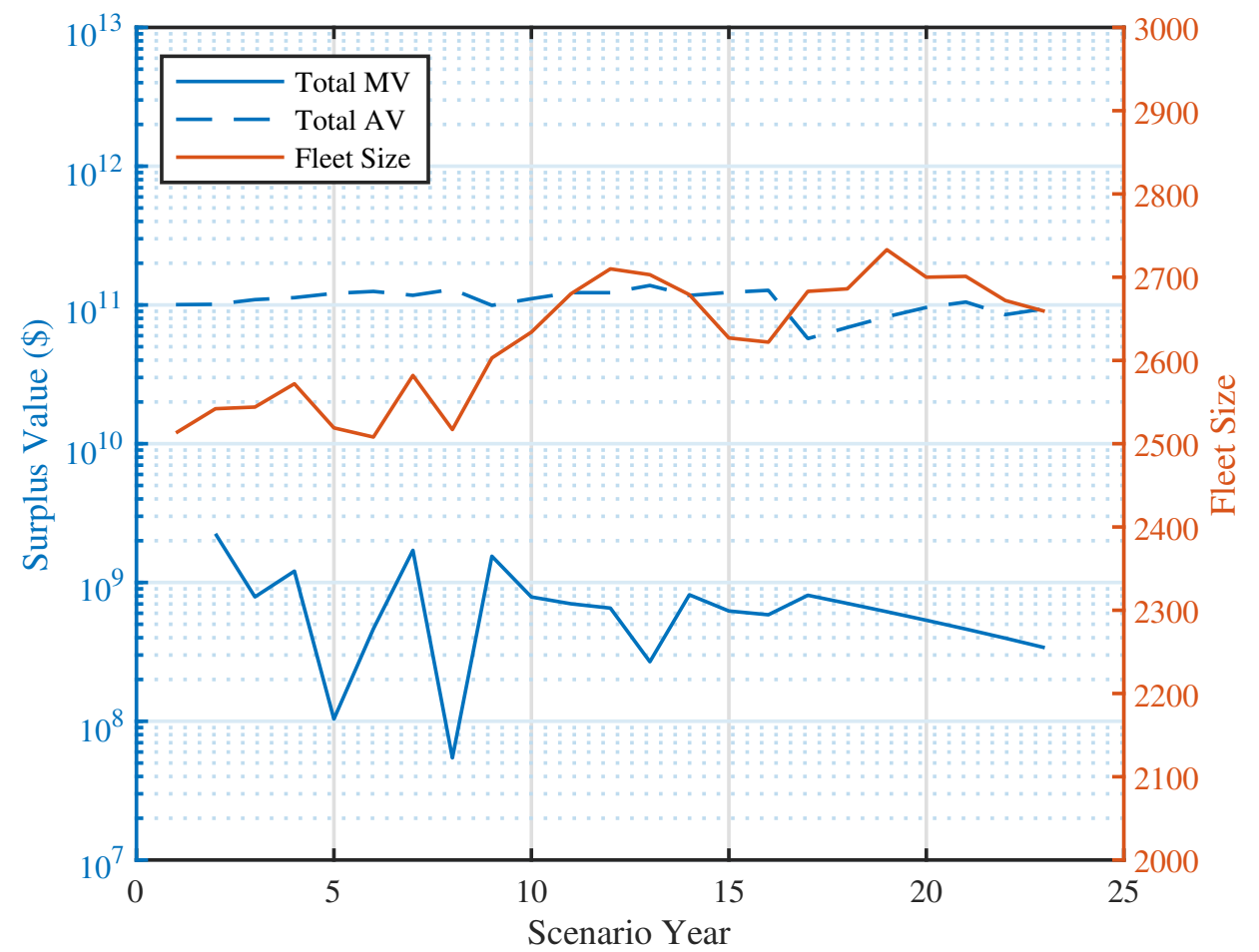

Fig. 6 Total fleet size and AV of each year within the MoM case study scenario 2, which includes the MoM A.2 aircraft only.

Scenario 5: Introducing the MoM, narrow-body, and wide-body aircraft

The fifth scenario includes the narrow-body Aircraft B and the wide-body Aircraft C as competitors to the MoM A.1 aircraft. This scenario is the most representative of the competition faced by the MoM, where both Boeing and Airbus offer single and twin aisle aircraft for this class.

Table 5 and Figure 7 presents the yearly fleet size, AV, and MV of the scenario. In this scenario, the total number of new aircraft sold increased compared to all the previous scenarios. Of the 2708 new aircraft sales, 1282 are the new wide-body aircraft and 820 are the new narrow-body aircraft. The total market SV also increased from the previous scenario from $\$ 3.0 \mathrm{~T}$ to $\$ 4.72 \mathrm{~T}$ but the MV of the MoM A.1 program reduced from $\$ 29.2 \mathrm{~B}$ to $\$ 9.8 \mathrm{~B}$. This is due to the MoM A.1 aircraft selling a total number of 606 aircraft, less than $70 \%$ than the previous scenario. These results are expected, as when additional competition is introduced, the MoM is squeezed and thus reduces the demand for the MoM aircraft.

Figure 7 shows that the total AV steadily increases over time as the airlines buy new aircraft to maximize AV. The total MV fluctuates around a relatively steady point, generating a similar amount of value each year. However, towards the end of the event horizon, the sales decrease as the airlines no longer require new aircraft. This is facilitated by two major retirements around years 2 and 17 as airlines buy new aircraft, which corresponds with a reduction in AV and an increased MV. 
Table 5 Total and individual fleet size, MV, AV, and SV of the MoM case study scenario 5, which includes MoM A.1, narrow-body aircraft $B$, and wide-body aircraft $C$.

\begin{tabular}{|c|c|c|c|c|c|}
\hline & \multicolumn{4}{|c|}{ Airline } & \multirow{2}{*}{ Total } \\
\hline & A & B & $\mathrm{C}$ & $\mathrm{D}$ & \\
\hline Fleet Size (Year 1) & 649 & 629 & 660 & 575 & 2513 \\
\hline Fleet Size (Year 23) & 617 & 614 & 585 & 568 & 2384 \\
\hline MoM A.1 Sold & 117 & 181 & 113 & 195 & 606 \\
\hline MoM A.1 AV (\$B) & -9.14 & 77.4 & 53.8 & 134 & 256 \\
\hline MoM A.1 MV (\$B) & 0.39 & 2.88 & 2.74 & 3.77 & 9.79 \\
\hline Aircraft B Sold & 504 & 125 & 41 & 150 & 820 \\
\hline Aircraft B AV (\$B) & 767 & 86.8 & 30.7 & 136 & 1020 \\
\hline Aircraft B MV (\$B) & 4.82 & 2.09 & 0.22 & 2.759 & 10.1 \\
\hline Aircraft C Sold & 0 & 453 & 528 & 301 & 1282 \\
\hline Aircraft C AV (\$B) & 0 & 499 & 737 & 277 & 1513 \\
\hline Aircraft C MV (\$B) & 0 & 18.4 & 30.1 & 11.75 & 60.0 \\
\hline $\mathrm{AV}(\$ \mathrm{~B})$ & 958 & 1332 & 1320 & 1031 & 4641 \\
\hline Market SV (\$B) & & & & & 4720 \\
\hline
\end{tabular}

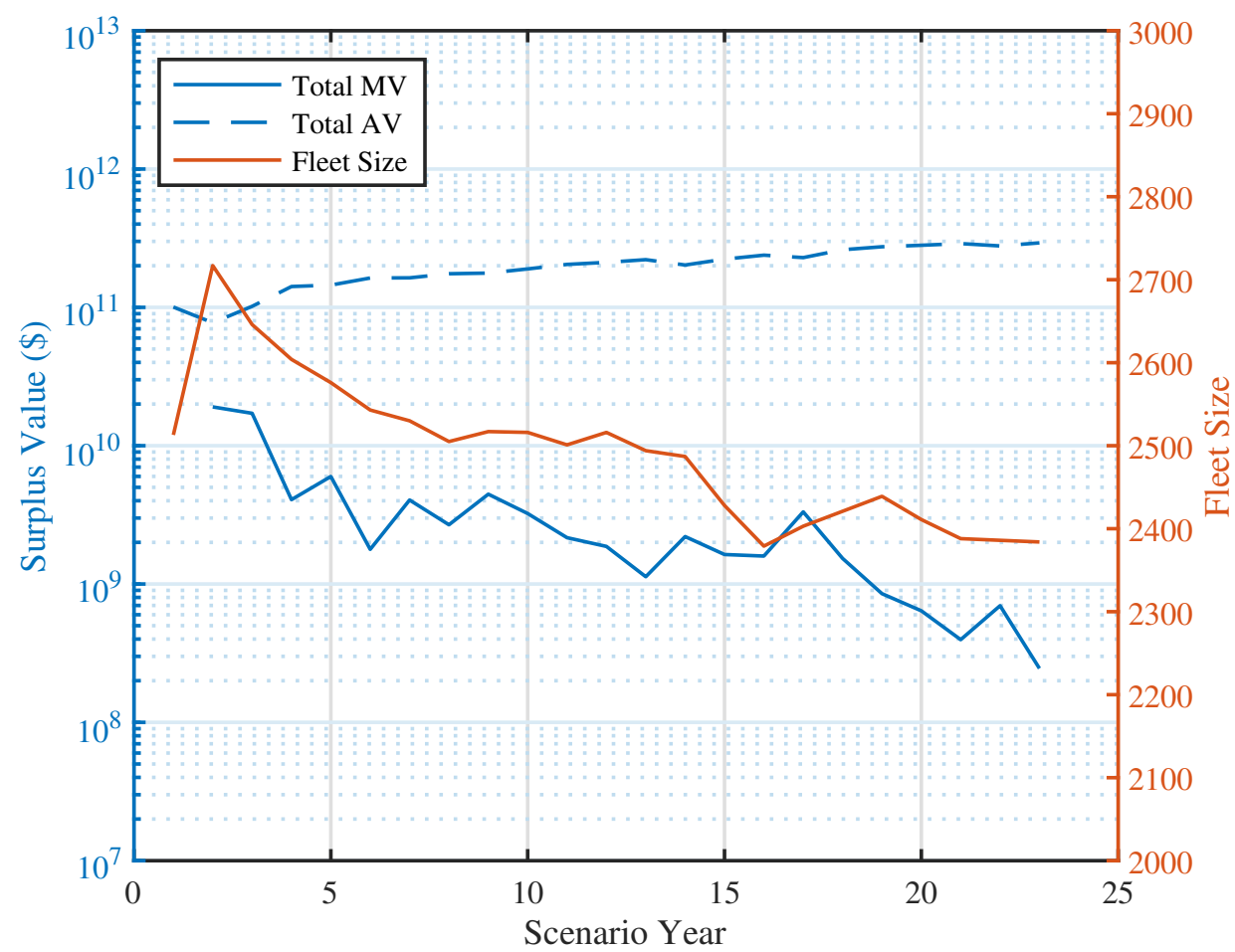

Fig. 7 Total fleet size and AV of each year within the MoM case study scenario 5, which includes MoM A.1, narrow-body aircraft $B$, and wide-body aircraft $C$.

\section{Comparing Market Demand Scenarios}

Figure 8 summarizes each scenario with the MoM A.1 aircraft, including an illustration of the total market SV, AV, $\mathrm{MV}$, and the total initial and final fleet size. At the beginning of each scenario, the total fleet size within the market is 
2513 aircraft, represented by the red line. Each bar represents a different competition scenario, where the size of the whole bar represents the total fleet size at the end of the event horizon. Each segment in the bar represents a different aircraft program, including information regarding the number of aircraft sold, the program SV, and MV. Each scenario is labelled according to the level of competition. The different scenarios show the change in the number of sales along with the value of each program depending on the competition within the market.

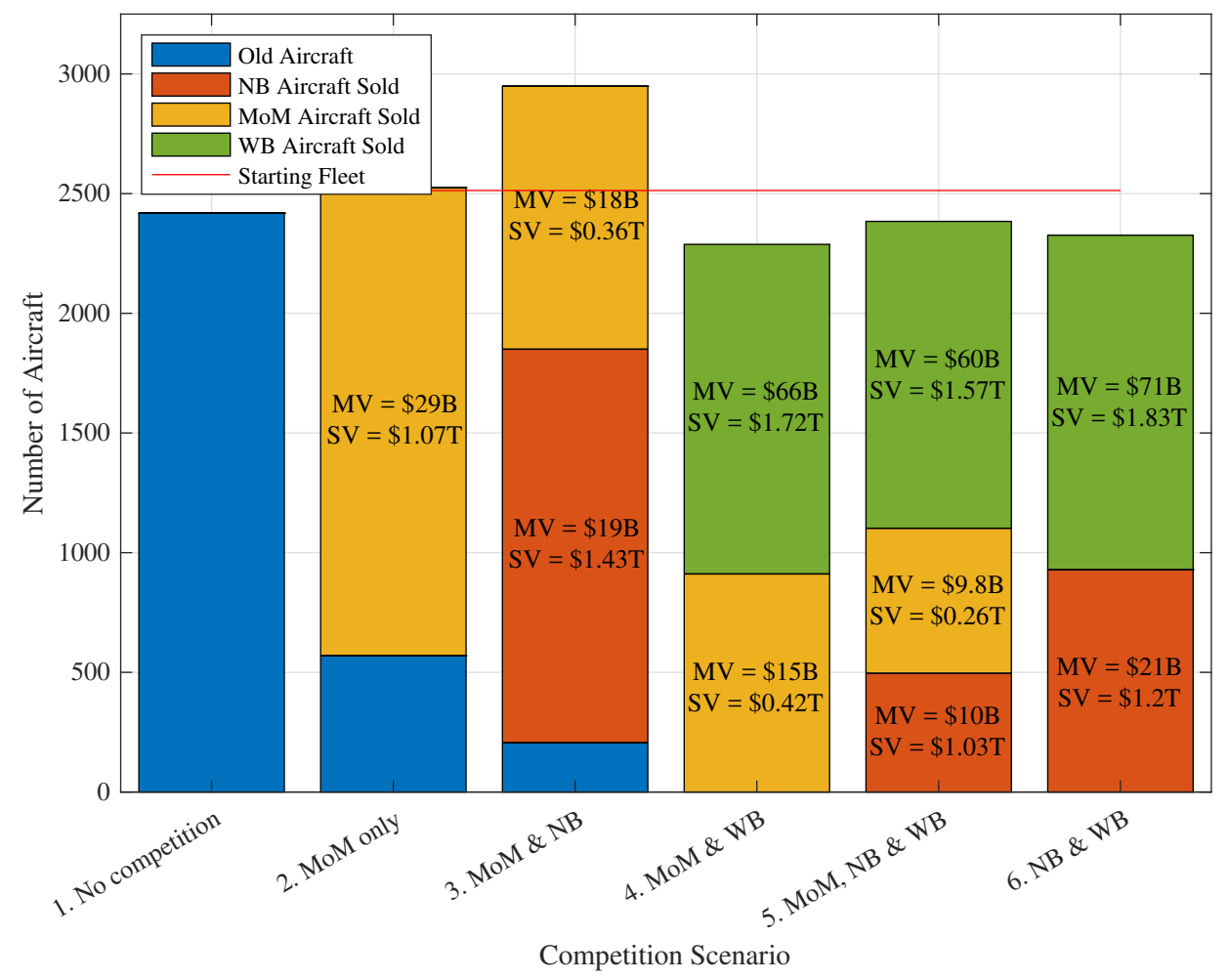

Fig. 8 Comparing the MoM case study scenarios using the MoM A.1 aircraft, which includes the total fleet size, SV, AV, and MV of each new program over the 23 year event horizon.

A similar summary is also created with MoM A.2, which is similar to MoM A.1 but with a lower aerodynamic and propulsive efficiency resulting in a lower payload-range capacity than MoM A.1. Generally, MoM A.2 provides less MV due to a lower market demand. Figure 9 contains information of how much MV is lost in each scenario, along with which competitors would gain as a result. For example, the fifth scenario provides the highest sales of new aircraft, the highest total market SV, and the highest revenue earned by the airlines and manufacturers combined. But with the MoM A.2, the $\mathrm{MV}$ of the program reduces by $\$ 10 \mathrm{~B}$, to a loss of $-\$ 1 \mathrm{~B}$, and the $\mathrm{MV}$ of the narrow-body aircraft and wide-body aircraft program increase by $\$ 8 \mathrm{~B}$ and $\$ 9 \mathrm{~B}$ respectively.

\section{Conclusions}

This paper demonstrates the effectiveness of a VDD framework for conceptual aircraft design. The framework enables design engineers and program-level decision makers with a clear and repeatable method that has the ability to 


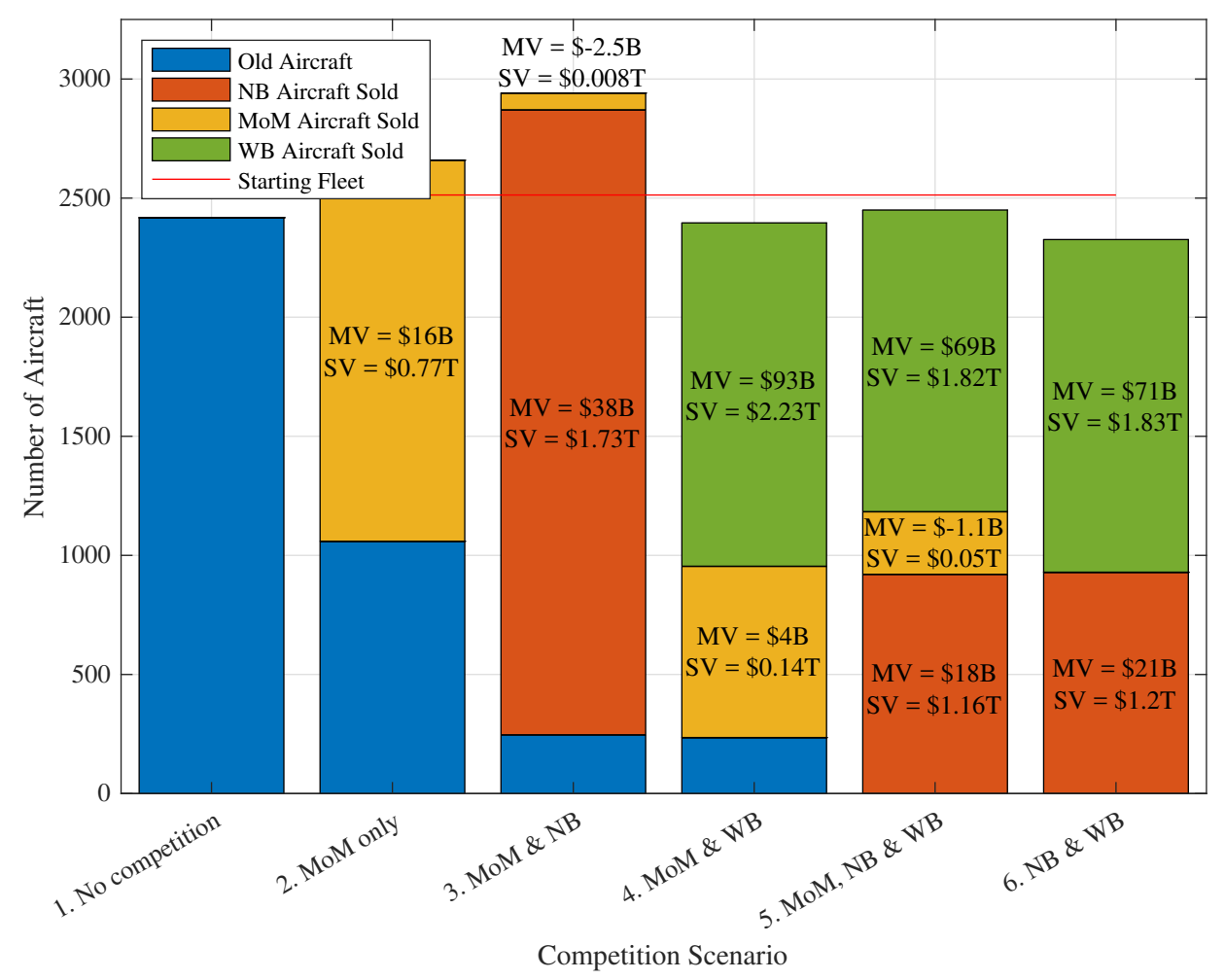

Fig. 9 Comparing the MoM case study scenarios using the MoM A.2 aircraft, which includes the total fleet size, SV, AV, and MV of each new program over the 23 year event horizon.

capture the effects of design parameters and competition on the market demand and value of the program.

A number of generally incorrect assumptions inherent to the simple SV equation are addressed within the proposed framework. These include the independence of the aircraft design on the market size, fixed revenues over the program life, and simple market dynamics. Addressing these assumptions extends the capabilities of the SV method, enabling design engineers to analyze the effects of the aircraft program value and the split in value between the stakeholders due to different aircraft designs, competitor aircraft designs and the decisions of other key market players.

The framework achieves this by employing several models to characterize the behaviour of the key players within the commercial aviation market and incorporates them together through a multi-stage non-cooperative game. The MoM was selected as a case study as it represents one of the major non-traditional markets currently within commercial aviation. Both the airlines and manufacturers are uncertain regarding the MoM demand and the basic aircraft required to serve it. Therefore, the proposed framework highlights the importance of using value in order to find and select the best course of action for the airlines and manufacturers.

As a baseline for the Middle of the Market case study, the simple SV equation calculated a program value between \$279B-\$713B, a range of over 250\%. A range was calculated to highlight one of the major issues within the simple SV equation: that an assumed potential demand is required for a given aircraft design over one average route. This disregards the airlines and their route structure, and the ability to fly multiple or different routes over the life of the 
aircraft. This demonstrated how the simple SV equation is highly uncertain compared to the framework as it varies greatly depending on these fixed inputs.

Six scenarios were presented using the framework with different levels of competition for two different MoM aircraft. The results showed that the demand and the value of the aircraft program depends on the number of competitors, the aircraft design, and competitor aircraft designs. This analysis along with the split in SV could not have been performed using the simple SV equation. Comparing the simple SV equation to the framework SV in Scenario 1 produced a difference of over $380 \%$. Therefore, the aircraft manufacturer would overestimate the market demand which would result in missed sales targets.

Another key outcome of the case study demonstrates the importance of the VDD framework to make informed decisions. For example, in the fifth scenario, the total market SV with the MoM A.2 aircraft is higher than the total market SV with the MoM A.1 aircraft, by $\$ 116 \mathrm{~B}$. This demonstrates why a manufacturer may not consider optimizing an aircraft design for the highest total market SV, as the results may suggest losing MV as the other key players can contribute more to the total SV. In the fifth scenario, the airlines generate \$108B more AV with MoM A.2 than MoM A.1. This result may seem counter-intuitive as MoM A.1 is technically a better performing aircraft. It is a general misconception to assume that the best performing design is the most valuable design. However, without the value information provided by this method, design engineers have no alternative but to make this assumption.

The reader should not take the results contained in this paper as representative of the actual outcome of a MoM market study. The MoM aircraft proposed in this analysis are generic un-optimized models; however, further work needs to be conducted with the framework and the SV method to find the optimum design for the MoM case study.

\section{Acknowledgments}

This work has been conducted through the School of Mechanical, Aerospace and Civil Engineering at The University of Manchester. The authors would like to thank Rolls-Royce plc, Product Cost Engineering, the United Kingdom—Her Majesty's Government Technology Strategy Board, Strategic Investment in Low-Carbon Engine Technology (UK-HMG, SILOET) program and The Engineering and Physical Sciences Research Council (EPSRC) for the funding and support of this project.

\section{References}

[1] Bloebaum, C. L., Hajela, P., and Sobieszczanski-Sobieski, J., "Non-Hierarchic System Decomposition in Structural Optimization,” Engineering Optimization, Vol. 19, No. 3, 1992, pp. 171-186. doi:10.1080/03052159208941227, URL https://doi .org/ 10. 1080/03052159208941227http://www.tandfonline.com/doi/abs/10. 1080/03052159208941227.

[2] Gates, D., “Boeing celebrates 787 delivery as program's costs top $\$ 32$ billion,”, 2011. URL http://old. seattletimes. com/html/businesstechnology/2016310102_boeing25.html. 
[3] Aboulafia, R., "Airbus A380: The Death Watch Begins," , 2016. URL https://www.forbes.com/sites/ richardaboulafia/2016/06/06/airbus-a380-the-final-countdown/\#698fa2c5553d.

[4] Matlack, C., “Airbus: First, Blame the Software,", 2006. URL https://www.bloomberg.com/news/articles/2006-1004/airbus-first-blame-the-software.

[5] Rothman, A., “Airbus A380 Is the Plane Airlines Aren’t Ordering Anymore,”, 2015. URL https://skift. com/2015/04/ 27/airbus-a380-is-the-plane-airlines-arent-ordering-anymore/.

[6] Bloebaum, C., "The Design of Large-Scale Complex Engineered Systems: Present Challenges and Future Promise," 12th AIAA Aviation Technology, Integration, and Operations (ATIO) Conference and 14th AIAA/ISSMO Multidisciplinary Analysis and Optimization Conference, 2012, pp. 1-19.

[7] Collopy, P., Bloebaum, C., Mesmer, B., and Green, L., “The distinct and interrelated roles of value-driven design, multidisciplinary design optimization, and decision analysis," 12th AIAA Aviation Technology, Integration, and Operations (ATIO) Conference and 14th AIAA/ISSMO Multidisciplinary Analysis and Optimization Conference, 2012, p. 5575.

[8] Hazelrigg, G. A., “A Framework for Decision-Based Engineering Design,” Journal of Mechanical Design, Vol. 120, No. 4, 1998, pp. 653-658. doi:10.1115/1.2829328, URL http://mechanicaldesign.asmedigitalcollection.asme.org/ article . aspx?articleid=1445465.

[9] Collopy, P. D., “A system for values, communication, and leadership in product design,” Tech. rep., Society of Automotive Engineers, 1996.

[10] Vengadasalam, L., Hollingsworth, P. M., and Smith, K., "Space Mission Architecture Design Philosophies and Methodologies A Review," 31st ISTS Open up a New Age of Space Discovery, International Symposium on Space Technology and Science, Matsuyama, 2017, pp. 1-8. URL http://archive.ists.or.jp/upload\{_\}pdf/2017-t-11.pdf.

[11] US Department of Defense Systems Management College, “Systems Engineering Fundementals,” Defence acquisition press, 2001, p. 222.

[12] Bloebaum, C. L., and McGowan, A.-M. R., "Design of complex engineered systems," Journal of Mechanical Design, 2010.

[13] Griffin, M. D., "How do we fix systems engineering?” 61st International Astronautical Congress, 2010, pp. 1-9.

[14] Felder, W. N., and Collopy, P., “The elephant in the mist: What we don't know about the design, development, test and management of complex systems," Journal of Aerospace Operations, Vol. 1, 2012, pp. 317-327.

[15] Hazelrigg, G. A., Systems Engineering: An Approach to Information-based Design, Prentice-Hall international series in industrial and systems engineering, Prentice Hall, Upper Saddle River, 1996. URL https://books.google.co.uk/books? id=Un5RAAAAMAAJ.

[16] Hazelrigg, G. A., "Validation of engineering design alternative selection methods," Engineering Optimization, Vol. 35, No. 2, 2003, pp. 103-120. doi:10.1080/0305215031000097059. 
[17] Hazelrigg, G. A., Fundamentals of Decision Making for Engineering Design and Systems Engineering, George A. Hazelrigg, Chalfont, 2012.

[18] Hazelrigg, G. A., “An Axiomatic Framework for Engineering Design,” Journal of Mechanical Design, Vol. 121, No. 3, 1999, pp. 342-347. doi:10.1115/1.2829466, URL http://mechanicaldesign.asmedigitalcollection.asme.org/article . aspx?articleid=1445646.

[19] Cheung, J., Scanlan, J., Wong, J., Forrester, J., Eres, H., Collopy, P., Hollingsworth, P., Wiseall, S., and Briceno, S., “Application of value-driven design to commercial aeroengine systems," Journal of Aircraft, Vol. 49, No. 3, 2012, pp. 688-702.

[20] Collopy, P., "Aerospace system value models: A survey and observations," AIAA Space 2009 Conference \& Exposition, 2009, p. 6560.

[21] Collopy, P. D., and Hollingsworth, P. M., "Value-driven design,” Journal of aircraft, Vol. 48, No. 3, 2011, pp. $749-759$.

[22] Hollingsworth, P., "An investigation of value modelling for commercial aircraft," Air Transport and Operations Symposium, Vol. 2012, 2011, pp. 358-371.

[23] Collopy, P. D., "Surplus Value in Propulsion System Design Optimization," 33rd AIAA Joint Propulsion Conference and Exhibit, Joint Propulsion Conferences, 1997.

[24] Hollingsworth, P., "Predicting Foreseeable Uncertainty Using a Value Driven Design Methodology," Air Transport and Operations: Proceedings of the Third International Air Transport and Operations Symposium 2012, 2012, p. 304.

[25] Castagne, S., Curran, R., and Collopy, P., "Implementation of value-driven optimisation for the design of aircraft fuselage panels," International journal of production economics, Vol. 117, No. 2, 2009, pp. 381-388.

[26] Collopy, P., and Horton, R., "Value modeling for technology evaluation," 38th AIAA/ASME/SAE/ASEE Joint Propulsion Conference \& Exhibit, 2002, p. 3622.

[27] Mullan, C., “An investigation into surplus value and its implications in aircraft design,” Ph.D. thesis, Queen's University Belfast, 2015.

[28] Berk, J., DeMarzo, P., Harford, J., Ford, G., Mollica, V., and Finch, N., Fundamentals of corporate finance, Pearson Higher Education AU, 2013.

[29] Sutcliffe, P., and Hollingsworth, P., "Development of an Airline Revenue Capability Model for Aircraft Design," 10th AIAA Aviation Technology, Integration, and Operations (ATIO) Conference, 2010, p. 9059.

[30] Soban, D. S., Price, M. A., and Hollingsworth, P., "Defining a research agenda in Value Driven Design: Questions that need to be asked," Journal of Aerospace Operations, Vol. 1, No. 4, 2012, pp. 329-342.

[31] Desai, A. A., Hollingsworth, P. M., and Chinchapatnam, P., "Identifying the best design for uncertain markets," 30th Congress of the International Council of the Aeronautical Sciences, ICAS 2016, 2016. 
[32] Vengadasalam, L., Desai, A., Hollingsworth, P., and Smith, K., "Value-Centric/Driven Design - A Framework," 31st ISTS Open up a New Age of Space Discovery, 2017, pp. 1-6.

[33] of Transportation Statistics, U. S. B., Transportation statistics annual report U.S. DOT Form 41 T-100 segment (all carriers), Bureau of Transportation Statistics, US Department of Transportation, 2017. URL http://www.rita.dot.gov/.

[34] McCullers, L. A., “FLOPS: Flight Optimization System-User's Guide,” NASA Langley Research Center, Vol. 348, 2002 , pp. 23681-0001.

[35] The Boeing Company, “737-600/-700/-800/-900/-900ER Flight Crew Operations Manual,”, 2012.

[36] The Boeing Company, "737 Airplane Characteristics for Airport Planning,”, 2013.

[37] The Boeing Company, "Flight Crew Operations Manual 757-200/-300,”, 2012.

[38] The Boeing Company, "757 Airplane Characteristics for Airport Planning,”, 2011.

[39] The Boeing Company, "Flight Crew Operations Manual 767-300,”, 2010.

[40] The Boeing Company, "767 Airplane Characteristics for Airport Planning,”, 2011.

[41] The Boeing Company, "Flight Crew Operations Manual 777-200/300,", 2010.

[42] The Boeing Company, "777 Airplane Characteristics for Airport Planning,”, 2011.

[43] The Boeing Company, "Flight Crew Operations Manual 787-800,”, 2008.

[44] The Boeing Company, "787 Airplane Characteristics for Airport Planning," , 2011.

[45] Airbus S.A.S, “A318/A319/A320/A321 Performance Training Manual,”, 2005.

[46] Airbus S.A.S, “A330 Flight Crew Training Manual,”, 2005.

[47] Airbus S.A.S, “A350 Flight Crew Training Manual,”, 2017.

[48] Airbus S.A.S, “A320 Aircraft Characteristics Airport And Maintenance Planning,”, 2015.

[49] Airbus S.A.S, “A330 Aircraft Characteristics Airport And Maintenance Planning,”, 2014.

[50] Airbus S.A.S, “A350 Aircraft Characteristics Airport And Maintenance Planning,”, 2016.

[51] Raymer, D. P., Aircraft Design: A Conceptual Approach, American Institute of Aeronautics and Astronautics, 2012.

[52] Flightglobal, "World Airliner Census,", 8 2017. URL https://www.flightglobal.com/asset/18365.

[53] Hepher, T., "Boeing sees potential for over 1,000 jets in mid-market," , 2015. URL https://uk.reuters.com/ article/us-airshow-france-boeing/boeing-sees-potential-for-over-1000-jets-in-mid-marketidUKKBNQOUQZX20150615. 